\title{
Infection-prevention measures against COVID-19 during anesthesia: a narrative review of current clinical literature
}

\author{
Yu Chen ${ }^{1 \#}$, Xiaoming Guo ${ }^{2 \#}$, Xiaoying Zhang ${ }^{3 \#}, \mathrm{Hao} \mathrm{Lv}^{1 \wedge}$ \\ ${ }^{1}$ Department of Anesthesiology, The Sixth Medical Center of Chinese PLA General Hospital, Beijing, China; ${ }^{2}$ Department of Anesthesiology, The \\ 900th Hospital of Joint Logistics Support Force, Fuzhou, China; ${ }^{3}$ Anesthesia and Operation Center, The First Medical Center of Chinese PLA \\ General Hospital, Beijing, China \\ Contributions: (I) Conception and design: All authors; (II) Administrative support: None; (III) Provision of study materials or patients: None; (IV) \\ Collection and assembly of data: Y Chen, X Zhang; (V) Data analysis and interpretation: Y Chen, X Guo; (VI) Manuscript writing: All authors; (VII) \\ Final approval of manuscript: All authors. \\ \#These authors contributed equally to this work. \\ Correspondence to: Hao Lv. Department of Anesthesiology, The sixth medical center of Chinese PLA General Hospital, 6 Fucheng Road, Haidian \\ District, Beijing 100048, China. Email: mzk6plagh@163.com.
}

\begin{abstract}
The outbreak of coronavirus disease 2019 (COVID-19) has increased the risk of infection among medical staff. Anesthetists may have direct or indirect contact with COVID-19 patients' saliva droplets, blood, and other secretions in their daily work. If infection-prevention measures are not appropriate, it will not only cause individual medical staff infection, but also cross-infection among patients and other medical staff. Therefore, it is important to establish infection-control practices for COVID-19 patients during anesthesia. The aim of the present study was to review the infection-prevention measures against COVID-19 during anesthesia. Previously published studies on severe acute respiratory syndrome (SARS) and Middle East respiratory syndrome (MERS), as well as current studies on COVID-19, specifically in Wuhan, China, were analyzed. In the present study, we discuss the etiology, epidemiology, pathology, clinical manifestations, diagnosis, and treatment of SARS, MERS, and COVID-19 at first. And then we discuss preoperative preparation which include the preparation of operating room, pre-operative assessment, hand hygiene and staffing and psychological counseling. We also discuss the implementation of anesthesia, including anesthesia types, induction of general anesthesia and endotracheal intubation, postoperative recovery and patient transport. Finally, we consider the proper disposal procedure for anesthetic equipment and medical devices. COVID-19 infection can be effectively reduced by infection-prevention measures during the perioperative period.
\end{abstract}

Keywords: Coronavirus disease 2019 (COVID-19); perioperative; infection-prevention measures; anesthesia

Submitted Sep 14, 2020. Accepted for publication Nov 06, 2020.

doi: 10.21037/apm-20-2073

View this article at: http://dx.doi.org/10.21037/apm-20-2073

\section{Introduction}

Since its outbreak in Wuhan in December 2019, coronavirus disease 2019 (COVID-19) has become a pandemic, with its rate of infection surpassing that of severe acute respiratory syndrome (SARS) and Middle East respiratory syndrome (MERS) (1). From December 2019 to February 2020, more than 3,000 medical staff in China and 27 other countries have been infected (2). Therefore, it is particularly important to increase the protection measures for medical staff. Anesthetists may have direct or indirect contact with COVID-19 patients' saliva droplets, blood,

^ ORCID: Yu Chen, 0000-0003-2545-794X; Hao Lv, 0000-0002-0175-6120. 
and other secretions in their daily work, and operating rooms and surgical departments are also prone to crossinfection. Therefore, in the present study, we summarize the infection-prevention measures against COVID-19 during anesthesia. Previously published studies on SARS and MERS, and current studies on COVID-19 in PubMed database and database of scientific papers and citations in China, specifically in Wuhan, China, were analyzed, as well as our experiences in hospitals in Hubei Province, to provide a reference for anesthetists of the importance of infection-prevention measures. We present the following article in accordance with the Narrative Review reporting checklist (available at http://dx.doi.org/10.21037/apm-202073).

\section{COVID-19 etiology}

Coronaviruses belong to the Coronaviridae family. COVID-19 is a novel coronavirus, and is usually round or oval in shape with a diameter of $60-140 \mathrm{~nm}$ (3); its characteristics differ to those of SARS-related coronavirus and MERS-related coronavirus (4). Its homology with bat-SARS-like coronavirus isolate 45 is currently $>85 \%$. COVID-19 can survive for 20-24 h in the air at room temperature, but 1-2 days in feces and urine. It is sensitive to ultraviolet rays and heat, only surviving for $30 \mathrm{~min}$ at $56{ }^{\circ} \mathrm{C}$. It can be effectively inactivated by ether, $75 \%$ ethanol, peracetic acid, or a chlorine containing disinfectant, with the exception of chlorhexidine.

\section{Epidemiology}

The primary route of transmission is through respiratory droplets or skin contact. Studies have shown that it can also be transmitted by fecal or aerosol-borne routes, but the clinical evidence is insufficient (5). It is easily transmissible among humans, especially elderly people with pre-existing diseases. The incidence rate of severe cases is about $20 \%$, and at April 19, 2020, the mortality rate was $2.5-12.8 \%$ (6).

\section{Pathology}

The pathological characteristics of COVID-19 are very similar to those of SARS and MERS, including its inflammatory response, which is characterized by deep airway and alveolar injury (7). The early stages of the disease include pulmonary edema, protein exudation, thickening of the pulmonary interstitium, infiltration of multinucleated giant cells, and macrophages in the alveoli. In the late stages of the disease, diffuse alveolar injury in both lungs is accompanied by fibromyxoid exudate, epithelial cells of the alveoli are exfoliated, and a hyaline membrane is formed (8).

\section{Clinical manifestation and treatment}

The incubation period of patients after COVID-19 infection is $3-7$ days, and no more than 14 days. The main manifestations are fever, fatigue, and dry cough. In severe cases, dyspnea often develops after 1 week. Critical cases can rapidly progress to ARDS, multiple organ failure, septic shock, metabolic acidosis, and coagulation dysfunction, which is difficult to correct (9). Imaging diagnosis is characterized by multiple small spot shadows and interstitial changes in the early stage, and multiple ground glass and infiltrative shadows in the progressive stage. Pulmonary consolidation can occur in severe cases, but pleural effusion rarely occurs (3).

At present, there is no specific drug available to cure COVID-19. Some clinical studies have shown that radcivir may be an effective drug to treat the disease in vitro (10). Recently, sample tests using chloroquine phosphate, fabiravir, and remdesivir have been done for large clinical trials in China to prove their safety and efficiency. According to Health Emergency Office of National Health Commission of the PRC for the diagnosis and treatment of COVID-19, traditional Chinese medicine and plasma therapy among convalescent patients have a positive effect, but need to be confirmed in clinical trials (3). It has been suggested that patients with mild infection should rest and undergo anti-infection and anti-virus treatment; severe cases should be treated in the intensive care unit (ICU) as early as possible (11).

\section{Diagnostic criteria}

COVID-19 is a new coronavirus that can cause fever and cough, and mild cases can rapidly develop into severe cases, including systemic inflammatory response syndrome and even multiple organ dysfunction syndrome. COVID-19 can be tested as soon as $15-30 \mathrm{~min}$, if suspected. Therefore, the Chinese Government suggests that all high-risk groups should be screened. However, according to Chinese National COVID-19 Diagnosis and Treatment Guidelines (trial version 7), the following 2 conditions should be regarded as suspected cases: (I) epidemic history +2 clinical manifestations; and (II) 3 clinical manifestations. 
Epidemic history includes travel to or living in Wuhan and surrounding areas within 14 days and contact with confirmed or suspected patients within 14 days. Clinical manifestations are as follows: (I) fever, cough, and other respiratory symptoms; (II) imaging manifestations of pneumonia; and (III) normal/decreased total number of leukocytes, and decreased percentage of lymph nodes.

To exclude suspected patients, the following conditions must be met: (I) novel coronavirus nucleic acids negative for detection (interval of at least $24 \mathrm{~h}$ ); (II) novel coronavirusspecific antibodies, immunoglobulin (Ig)M and IgG, remain negative after 7 days of onset. Therefore, suspected patients can be completely excluded from being infected with COVID-19 after at least 7 days.

If one of the following 3 points can be confirmed, a suspected case becomes a confirmed case: (I) novel coronavirus nucleic acids are positive for detection; (II) viral gene sequencing is highly consistent with COVID-19; and (III) novel coronavirus-specific antibodies, IgM and IgG, are positive.

\section{Curative criteria}

The following conditions are required for discharge: (I) body temperature remains normal for $>3$ days; (II) symptoms and imaging manifestations improve significantly; and (III) 2 novel coronavirus nucleic acids are negative for detection (interval of at least $24 \mathrm{~h}$ ).

\section{Infection-prevention measures during anesthesia}

Patients requiring emergency surgery should complete primary triage prior to hospital admission. A secondary triage before entering the operating room should be performed by anesthetists. This triage should include reviewing medical history, a brief physical examination, and reviewing chest computed tomography or chest X-ray. Body temperature should be retaken. Individuals who are considered not to have COVID-19 should undergo their surgical procedure as normal if it is an emergency surgery (11). If urgent life-saving surgery is required and there is no time to do the relevant examination, the patient should be treated as a confirmed or suspected COVID-19 case. Only emergency surgeries can be performed, and elective surgeries should be delayed until the patient no longer has COVID-19. The following measures can be applied to patients who are confirmed or suspected infection of COVID-19.

\section{Preoperative preparation}

\section{Operating room}

Staff procedural duties for COVID-19 should be fulfilled in an expeditious and orderly fashion to minimize infection risk. The doctor on duty should report to the infection control officer of the hospital as soon as they are informed of a COVID-19 patient. Next, the circulating nurse should prepare the designated operating room(s) for those infected with the virus. If necessary, inform the laminar flow technician to check and replace the negative pressure filter in the operating room. The filter must be negative; it is not, it is recommended that the positive pressure or air conditioning is switched off (to decrease circulation). The buffer room should be closed before the operation. Once the operation room has negative pressure $(<-5 \mathrm{~Pa})$, operations can commence $(12,13)$. A designated operating room for patients with COVID-19 must have a "Caution: infectious surgery room" sign on the door. Only staff involved in the surgery are allowed to enter this room. Staff must also wear personal protective equipment, and facilities should be disinfected in order to be thoroughly prepared to prevent spread (14).

\section{Preoperative assessment}

Anesthetists need to pay particular attention to pulmonary infection development and the general state of patients, in addition to the routine diagnostics. Patients with a severe infection should be moved to the ICU isolation ward prior to surgery. Anesthetists should routinely prepare enough drugs and supplies for anesthesia and the surgery, and perform personal precautionary measures before patient contact. Precautions include medical standard handwashing, a medical protective mask, a disposable surgical cap and goggles/protective screen, C-class protective clothing outside, double latex gloves, and shoe covers (15). In their study, Birnbach et al. stated that double latex gloves can provide better protection than single latex gloves (16). Please refer to Table 1 for specific steps of wearing and removing sequence.

\section{Hand hygiene}

Anesthetists and other medical staff must ensure good hand hygiene. Hand-mediated transmission is the major contributing factor to infection associated with healthcare professionals. Effective hand decontamination immediately before every episode of direct patient contact will result in a significant reduction in the transfer of potential pathogens 
Table 1 Infection-prevention measures for anesthetists before and after patient contact

\begin{tabular}{lll}
\hline Steps & Before patient contact & After patient contact \\
\hline 1 & Hand disinfection & Remove shoe covers \\
2 & Surgical cap & Remove double latex gloves \\
3 & Medical protective mask & Hand disinfection \\
4 & Goggles/protective screen & Remove goggles/protective screen \\
5 & C-class protective clothing & Hand disinfection \\
6 & Shoe covers & Remove medical protective mask \\
7 & Double latex gloves & Hand disinfection \\
8 & & Remove surgical cap \\
9 & & Hand disinfection \\
10 & & Take a hot bath and change personal clothes \\
\hline
\end{tabular}

and a decrease in the cumulative incidence. At the start of every session, and when visibly soiled or potentially contaminated, hands must be washed with liquid soap and water. It is vital to ensure that the whole hand, fingers, and just above the wrists are thoroughly washed (17).

\section{Staff counseling}

It is highly recommended that staff with knowledge of infectious diseases are selected and that only the experienced anesthetists and nurses partake in surgeries involving COVID-19-infected patients. Anesthetists who have entered the contaminated operating room should not leave, and anesthetists outside the room should not enter and only transfer supplies in the buffer room with the one inside (18). In addition, counseling should be provided to anesthetists and nurses to overcome their fears in advance (19). Particular attention should be paid to selfprotection and avoiding sharp instrument damage.

\section{Anesthetic implementation}

\section{Anesthetic type}

General anesthesia is recommended to reduce the spread of air and droplets from the patient's mouth and nose. Other anesthetic types can be administered according to the situation, as long as the airway is protected (11). Wearing a protective mask around the patient in the operating room is highly recommended if the patient is not intubated. Intraspinal anesthesia is still recommended for cesarean section patients with COVID-19. Pregnant women should wear a medical protective mask to reduce air transmission, and precautionary measures should be considered for infants (20).

\section{General anesthesia and endotracheal intubation}

This is a critical step with the highest probability of infection transmission for anesthetists. In a retrospective cohort study, 624 medical staff who had close contact with 45 SARS patients with tracheal intubation were analyzed. The results showed that 7 SARS patients infected 26 medical staff, and 3 SARS patients infected 21 medical staff, and the route of infection was most likely aerosol borne (21). Therefore, personal protective measures must be carried out before endotracheal intubation.

Reducing the cough response during endotracheal intubation is important. Some studies have shown that $1.0-1.5 \mathrm{mg} / \mathrm{kg}$ lidocaine or $0.5 \mathrm{\mu g} / \mathrm{kg}$ dexmedetomidine prior to induction could reduce the cough response during endotracheal intubation. The speed of the opioid injection should be slowed down to avoid a choking cough during induction, and it is important to use a sufficient dose of neuromuscular blockers (22).

Intravenous fast induction is encouraged, and the corresponding intubation tools should be prepared prior to surgery for patients with airway difficulties. A skilled anesthetist with experience in airway management should use the most appropriate tracheal intubation tools to complete the operation. It is recommended that a visual 
laryngoscope with a disposable laryngoscope lens be used, and that a protective sleeve to protect both the display and lens handle is utilized (23). Oxygen can be given at a highflow rate for $5 \mathrm{~min}$ before sequential induction. An artificial positive pressure mask for ventilation during induction must not be used (unless absolutely necessary) to help prevent aerosol diffusion. If positive pressure ventilation is necessary then the patient's nose and mouth should be covered with 2 pieces of wet gauze (11). Appropriate sedatives, analgesics, and sufficient neuromuscular blocking agents should be administered, taking into consideration the patient's condition, to avoid a choking cough and droplet diffusion during tracheal intubation. It is important to utilize closed sputum aspirator. After endotracheal intubation, all intubation supplies should be immediately placed into double sealed bags and then decontaminated or discarded (24,25). Artificial nose is recommended for use during the operation to prevent the anesthetic machine from being contaminated, and should be replaced every 3$4 \mathrm{~h}$ (26). Based on SARS and MERS experience in previously published studies, the pulmonary protective ventilation strategy for intraoperative mechanical ventilation is recommended for asymptomatic or mildly infected patients, as it has a low tidal volume $(5-6 \mathrm{~mL} / \mathrm{kg})$ and has a suitable positive end-expiratory pressure (with a 0-5 PEEP) $(3,27)$. Individualized ventilation strategies should be developed for critical patients based on the change in lung function.

\section{Anesthetic recovery}

Patients should be sent to the ICU isolation ward after the operation. The tracheal tube should be removed when vital signs are stable and the anesthetic drugs are fully metabolized. Before extubation, pieces of gauze should be used to cover the patient's mouth to reduce the spatter caused by cough (11). Studies have shown that an intravenous lidocaine injection $(1.0-1.5 \mathrm{mg} / \mathrm{kg})$ or intratracheal spray $(1 \mathrm{mg} / \mathrm{kg})$ prior to tracheal extubation can effectively prevent cough (22).

\section{Patient transport}

The patient should be covered with a single sheet before transport, and then moved by a patient transport elevator. The transfer channel should be evacuated in advance to reduce exposure to others (28). Patients should wear a medical protective mask if there is no tracheal intubation (29). Once transported, a comprehensive handover should be completed at the new unit.

\section{Disposal of medical supplies, and staff management after operation}

\section{Medical waste}

Material waste should be documented, labeled, and disposed of quickly to ensure the safety of personnel and to reduce the risk of infection (30). An additional disposal bag should enclose the garbage bag, and the sharps box should be separately secured in the hazards disposal. A COVID-19 label should be attached to each packaged waste item, along with identification of the unit, department and date (11). The packaging bag should be sealed before leaving the contamination zone, and the surface should be sterilized by spraying a disinfectant solution containing chlorine.

\section{Disinfection of the operating room}

The designated COVID-19 operating room should be fully disinfected through a series of steps. It is recommended that instruments are sterilized or placed in a proper storage location before disinfection. At the very least, the instruments in the operating room should be protected with a protective sheath to avoid corrosion. Laminar flow should be closed and the operating room should be sealed during the disinfection process, which should take 1-2 h; a peracetic acid spray sterilizer or dual-mode hydrogen peroxide robot disinfector should be used for disinfection. Open the laminar flow after completing the disinfection; 2,000-5,000 mg/L chlorine containing disinfectant should be used on the ground or the surface of equipment that had contact with blood and/or body fluid for at least $30 \mathrm{~min}$, and $1,000-2,000 \mathrm{mg} / \mathrm{L}$ chlorine containing disinfectant should be used on the surface of equipment without blood or body fluid for 10-30 min and then mopped with clean water $(31,32)$. Before cleaning, the janitor should receive specialized training to ensure proper cleaning and safety for all staff involved. The cleaning duties should be completed by the hospital janitor and the medical staff.

\section{Disinfection of transfer bed}

The transfer bed should be cleaned, and the mattress should be dismantled and erected. The transfer bed should be transferred to the used operating room before disinfection, and disinfected using the peracetic acid spray sterilizer or 
dual-mode hydrogen peroxide robot disinfector (3). The surface of the transfer bed should be treated the same as the surface of equipment in the operation room.

\section{Staff management after operation}

All medical staff involved in the operation need to be observed for 2 weeks and should reduce direct contact with others. Their temperature and other symptoms should be recorded $(3,11)$. If there are any abnormalities during observations, pathogen detection should be implemented.

\section{Disposal of anesthetic equipment}

The purpose of disinfecting anesthetic equipment is to reduce the spread of the virus among patients. Disposable anesthetic supplies should be used as much as possible, such as tracheal tubes, laryngoscopes, dental pads, suction tubes, suction devices, masks, snails, and mosquito tubes (17). The dismantled part of the laryngoscope and the anesthetic machine should be removed for thorough disinfection.

\section{Disposable anesthetic supplies}

After the operation, disposable supplies should be placed into bags identified as "medical waste" with special COVID-19 labels and discarded. Reusing disposable materials and equipment exponentially increases the spread and infection risk for anyone who comes into contact with the items.

\section{Reusable anesthetic supplies}

The non-disposable part of the laryngoscope or visual laryngoscope should be covered with a disposable protective cover prior to use, and the protective cover should be discarded after use. Equipment, such as fiberoptic bronchoscopes, rigid bronchoscopes, and nerve stimulators, should be washed and sterilized according to the disinfection standard for medical equipment by patients with a special infection (33).

\section{Anesthetic machine decontamination}

Compound alcohol disinfector should be used to disinfect the inner respiratory circuit after the operation. The disinfectant used in the compound alcohol sterilizer is ethanol, which is distributed in the breathing circuit of the anesthetic machine by air pressure plasma atomization.
The breathing circuit in the anesthetic machine is connected to the disinfection machine circuit through the threaded pipe, without dismantling the anesthetic machine for atomization sterilization, for $10 \mathrm{~min}$ and analytical drying for $20 \mathrm{~min}$ (34). The are several advantages of this method, including corrosiveness reduction, convenience during operation, and effective and concise disinfection. It should be kept in mind when handling that it is a fire hazard, and to refrain from using around fire or flames. Upon initial use, it is highly recommended that personnel handling the anesthetic machine are the first to use it and then train others appropriately under strict guidance (35).

\section{Conclusions}

In the present study, we analyzed the etiology, epidemiology, pathology, clinical manifestation, diagnosis, and treatment of COVID-19, and discussed preoperative preparation, the implementation of anesthesia, and postoperative recovery and patient transport. We also discussed the disposal of anesthetic equipment and medical devices. It is believed that COVID-19 infection can be effectively reduced by a series of infection-prevention measures in the perioperative stage of treatment. However, because of the short time of onset, many conclusions are based on the experiences of the first-line medical staff observing the efficacy, and there is still a lack of perfect design and research implementation to support, and further studies are warranted.

\section{Acknowledgments}

We thank Professor Jun Li, the President of Perioperative Infection Control Society of the Chinese Society of Cardiothoracic and Vascular Anesthesia, for his guidance, and Professor Heather B Wallace (USA) and Professor Jiali Cai (Jiangnan University, China) for proofreading the article.

Funding: Financial support and sponsorship: Innovation and cultivation fund of the Navy General Hospital in China (No. CXPY2017033).

\section{Footnote}

Reporting Checklist: The authors have completed the Narrative Review reporting checklist. Available at http:// dx.doi.org/10.21037/apm-20-2073

Conflicts of Interest: All authors have completed the ICMJE 
uniform disclosure form (available at http://dx.doi. org/10.21037/apm-20-2073). The authors have no conflicts of interest to declare.

Ethical Statement: The authors are accountable for all aspects of the work in ensuring that questions related to the accuracy or integrity of any part of the work are appropriately investigated and resolved.

Open Access Statement: This is an Open Access article distributed in accordance with the Creative Commons Attribution-NonCommercial-NoDerivs 4.0 International License (CC BY-NC-ND 4.0), which permits the noncommercial replication and distribution of the article with the strict proviso that no changes or edits are made and the original work is properly cited (including links to both the formal publication through the relevant DOI and the license). See: https://creativecommons.org/licenses/by-nc-nd/4.0/.

\section{References}

1. Huang C, Wang Y, Li X, et al. Clinical features of patients infected with 2019 novel coronavirus in Wuhan, China.

Lancet 2020;395:497-506.

2. World Health Organization: Rational use of personal protective equipment for coronavirus disease 2019 (COVID-19). Interim guidance. Accessed February 27, 2020. Available online: https://www.who.int/emergencies/ diseases/novel-corona-virus-2019/technical-guidance/ infection-prevention-and-control

3. Health Emergency Office of National Health Commission of the PRC. Update on the diagnosis and treatment of 2019 Novel coronavirus pneumonia (COVID-19) (The Sixth Edition). Accessed February 18, 2020. Available online: http://www.nhc.gov.cn/yzygj/s7653p/202002/8334 a8326dd94d329df351d-7da8aefc2.shtml

4. Prompetchara E, Ketloy C, Palaga T. Immune responses in COVID-19 and potential vaccines: Lessons learned from SARS and MERS epidemic. Asian Pac J Allergy Immunol 2020;38:1-9.

5. Respiratory care committee of Chinese Thoracic Society. Expert consensus on preventing nosocomial transmission during respiratory care for critically ill patients infected by 2019 novel coronavirus pneumonia. Chin J Tubere Respir Dis 2020;17:E020.

6. Abd El-Aziz TM, Stockand JD. Recent progress and challenges in drug development against COVID-19 coronavirus (SARS-CoV-2) - an update on the status.
Infect Genet Evol 2020;83:104327.

7. Wang HJ, Du SH, Yue X, et al. Review and Prospect of Pathological Features of Corona Virus Disease. Journal of Forensic Medicine 2020;36:16-20.

8. Liu Q, Wang RS, Qu GL, et al. Anatomical observation of a novel coronavirus pneumonia death body. Journal of Forensic Medicine 2020;36:21-3.

9. Jin $\mathrm{YH}$, Cai L, Cheng ZS, et al. A rapid advice guideline for the diagnosis and treatment of 2019 novel coronavirus (2019-nCoV) infected pneumonia (Full version). J New Med 2020;30:35-64.

10. Wang M, Cao R, Zhang L, et al. Remdesivir and chloroquine effectively inhibit the recently emerged novel coronavirus $(2019-\mathrm{nCoV})$ in vitro. Cell Res 2020;30:269-71.

11. Perioperative Infection Control Society of Chinese Society of Cardiothoracic and Vascular Anesthesia, PLA Society of Anesthesiology and Resuscitation. Recommendation for perioperative infection control in patients with 2019 Novel coronavirus pneumonia (COVID-19). Preoperative Safety and Quality Assurance 2020;4:63-6.

12. Scheithauer S, Rosarius A, Rex S, et al. Improving hand hygiene compliance in the anesthesia working room work area: more than just more hand rubs. Am J Infect Control 2013;41:1001-6.

13. Ryan AJ, Webster CS, Merry AF, et al. A national survey of infection control practice by New Zealand anaesthetists. Anaesth Intensive Care 2006;34:68-74.

14. Park J, Yoo SY, Ko JH, et al. Infection Prevention Measures for Surgical Procedures during a Middle East Respiratory Syndrome Outbreak in a Tertiary Care Hospital in South Korea. Sci Rep 2020;10:325.

15. Chen WQ, Ling WH, Lu CY, et al. Which preventive measures might protect health care workers from SARS? BMC Public Health 2009;9:81.

16. Birnbach DJ, Rosen LF, Fitzpatrick M, et al. Double gloves: a randomized trial to evaluate a simple strategy to reduce contamination in the operating room. Anesth Analg 2015;120:848-52.

17. Association of Anaesthetists of Great Britain and Ireland (AAGBI). Infection Control in Anaesthesia. Anaesthesia 2008;63:1027-36.

18. Missair A, Marino MJ, Vu CN, et al. Anesthetic implications of Ebola patient management: a review of the literature and policies. Anesthesia Analgesia 2015;121:810-21.

19. Wu P, Fang YY, Guan ZQ, et al. The Psychological Impact of the SARS Epidemic on Hospital Employees in China: 
Exposure, Risk Perception, and Altruistic Acceptance of Risk. Can J Psychiatry 2009;54:302-11.

20. Maxwell C, Mcgeer A, Tai KY, et al. Management guidelines for obstetric patients and neonates born to mothers with suspected or probable severe acute respiratory syndrome (SARS). J Obstet Gynaecol Can 2017;39:e130-7.

21. Raboud J, Shigayeva A, McGeer A, et al. Risk factors for SARS transmission from patients requiring intubation: a multicentre investigation in Toronto, Canada. PLoS One 2010;5:e10717.

22. Jalali A, Nasiri E, Khoramian M, et al. Hemodynamic Responses to Tracheal Intubation in Elderly Patients: Intravenous or Spray of Lidocaine versus Fentanyl. Med Arch 2017;71:424-9.

23. Cooper A, Joglekar A, Adhikari N. A practical approach to airway management in patients with SARS. CMAJ 2003;169:785-7.

24. Tran K, Cimon K, Severn M, et al. Aerosol generating procedures and risk of transmission of acute respiratory infections to healthcare workers: a systematic review. PLoS One 2012;7:e35797.

25. Wong DT. Protection protocol in intubation of suspected SARS patients. Can J Anaesth 2003;50:747-8.

26. Ryan AJ, Webster CS, Merry AF, A national survey of infection control practice by New Zealand anaesthetists. Anaesth Intensive Care 2006;34:68-74.

27. Dyall J, Gross R, Kindrachuk J, et al. Middle East Respiratory Syndrome and Severe Acute Respiratory Syndrome: Current Therapeutic Options and Potential Targets for Novel Therapies. Drugs 2017;77:1935-66.

28. Chen X, Liu YH, Gong YH, et al. Perioperative

Cite this article as: Chen Y, Guo X, Zhang X, Lv H. Infectionprevention measures against COVID-19 during anesthesia: a narrative review of current clinical literature. Ann Palliat Med 2020;9(6):4300-4307. doi: 10.21037/apm-20-2073
Management of Patients Infected with the Novel Coronavirus. Anesthesiology 2020;132:1307-16.

29. Nanji KC, Orser BA. Managing Ebola: Lessons Learned from the SARS Epidemic. Anesth Analg 2015;121:834-5.

30. Yu H, Sun X, Deng W, et al. Reverse Logistics Network Design for Effective Management of Medical Waste in Epidemic Outbreaks: Insights from the Coronavirus Disease 2019 (COVID-19) Outbreak in Wuhan (China). Int J Environ Res Public Health 2020;17:1770.

31. Zhang B, Li L, Yao X, et al. Analysis of Air Purification Methods in Operating Rooms of Chinese Hospitals. Biomed Res Int 2020;8278943.

32. Humayun T, Qureshi A, Roweily SF, et al. Efficacy Of Hydrogen Peroxide Fumigation In Improving Disinfection Of Hospital Rooms And Reducing The Number Of Microorganisms. J Ayub Med Coll Abbottabad 2019;31:S646-50.

33. Peng PW, Wong DT, Bevan D, et al. Infection control and anesthesia: lessons learned from the Toronto SARS outbreak. Can J Anaesth 2003;50:989-97.

34. Perioperative Infection Control Society of Chinese Society of Cardiothoracic and Vascular Anesthesia Task Force on disinfection and sterilization of breathing circuit in anesthesia machine. Recommendation for disinfection and sterilization of breathing circuit in anesthesia machine. Chin J Anesthesiol 2018;12:1417-20.

35. Tablan OC, Anderson LJ, Besser R, et al. Guidelines for preventing health-care-associated pneumonia, 2003. MMWR Recomm Rep 2004;53:1-36.

(English Language Editor: R. Scott) 